\title{
Biochemical, Organoleptic Assessment of Fig (Ficus Carica)
}

\author{
Dr. Jyoti D.Vora ${ }^{1}$, Dr. Dipak Vora ${ }^{2}$, Ms. Sneha R. Pednekar ${ }^{3}$, \\ Ms. Aditi U. Patwardhan ${ }^{4}$, Ms. Sheeba Shaikh ${ }^{5}$ \\ ${ }^{1 .}$ Head, Department of Biochemistry and Food Science and Quality Control, Ramnarain Ruia College, \\ Matunga, Mumbai-400019, Maharashtra. \\ 2. Associate Professor, Department of Microbiology, Ramnarain Ruia College, Matunga, Mumbai-400019, \\ Maharashtra. \\ 3. Assistant Professor, Department of Biochemistry and Food Science and Quality Control, Ramnarain Ruia \\ College, Matunga, Mumbai-400019, Maharashtra. \\ 4. Assistant Professor, Department of Biochemistry and Food Science and Quality Control, Ramnarain Ruia \\ College, Matunga, Mumbai-400019, Maharashtra. \\ 5. Student, Department of Biochemistry and Food Science and Quality Control, Ramnarain Ruia College, \\ Matunga, Mumbai-400019, Maharashtra.
}

\begin{abstract}
The fig (Ficus carica) is widely cultivated plant in the mulberry family (Moraceae). Ficus carica grows in tropical and sub-tropical regions of India. A wide range of size, shape (round, oblate and oblong) and colour (yellow green, purple green and purple black) are found. The plant has a great involvement in curing many diseases and is used as a medicinal plant. They are consumed fresh as well as in the dried form among the masses. For this reason, comparative studies were carried out for establishing the nutritional profiles of fresh fig fruit and dried fig fruit. To substantiate this, an analysis of the proximate analysis of the samples was carried out using bench science experiments. The proximate profiles of carbohydrates, minerals, proteins and dietary fiber were analysed. The study showed highest percentage of dietary fiber, potassium and calcium and considerable amounts of proteins, carbohydrates, iron, phosphorous, vitamin C. Further in order to project the organoleptic appeal of fig under study, invasive and non-invasive sensory evaluation was carried out by a semi-trained panelist. This was executed with a recipe. The data was subjected to biostatistical analysis which proved that the fig recipe was accepted. Thus, studies related to identification of the bioactive compounds and correlating them to their biological activities are very useful for further research to explore the potential of fig (Ficus carica) as a source of therapeutic agents and also may be utilized as nutraceutical food with high nutrition.
\end{abstract}

Keywords: Fresh Fig, Dried Fig, Comparative studies, Sensory Evaluation, Biostatistical analysis, Therapeutic agents, Nutraceuticalfood.

\section{Introduction}

Food is one of the basic necessities of life. Food appeals to the senses, nourishes the body and satiates the soul. Since ancient times, food is recognized as the most superior source contributing to human wellness. Thus, there is no doubt that food is the epicenter of human living. Thus food is not just a medium of nourishment, but also a mode of elevating the physical, emotional and spiritual quotient of an individual. Thus, for all these reasons, food is indeed the gateway to health.

Modern lifestyles are fast-paced and hectic. There is no time for a breather, let alone dedicated and regular mealtimes. This has led to the human population compromising their health due to inadequate and imbalanced nutrition. To somewhat address this problem; a new trend has evolved in the field of food science and technology that is the development of convenience foods. Convenience foods as the name suggests are food products developed which are poised on the fulcrum of consumer convenience. These foods promise to greatly reduce the time required in procuring, processing and preparation of foods. Innovative foods labeled ready to eat, ready to cook, instant foods are all prominent examples of convenience foods. Due to this manufacturing initiative, consumers do not have to skip meals, as these foods can be easily consumed on the go.

However, as humans are psychosocial and highly intellectual, there is a cognitive and emotional association with food. Food is only aptly consumed when it precisely appeals to all the senses- sight, smell, taste, touch and also auditory. Thus, innovative products promising maximum consumer convenience are rendered useless if they do not meet the criteria of organoleptic acceptability. Thus, Sensory Evaluation, the science of measurement and quantification of organoleptic acceptability using the senses is the one of foundations of product development. 


\section{About Fig (Ficus carica):}

Ficus carica, the Common fig is a deciduous shrub or small tree belonging to the Moraceae (mulberry family) is one of the most ancient fruit crops grown in temperate regions worldwide for its delicious "fruits". The mention of figs in culture dates as far as the era of Adam and Eve where it was considered to be a divine fruit or the fruit of paradise. It was mused the symbol of abundance in various cultures worldwide. The idiom "sitting under one's own fig tree" was said to be used widely in ancient tribes as a sign of wealth.

Figs range dramatically in color and subtly in texture depending upon the variety, of which there are more than one hundred and fifty.

Some of the most popular varieties of figs are:

- Black Mission: blackish-purple skin and pink-colored flesh

- Kadota: green skin and purplish flesh

- Calimyrna: greenish-yellow skin and amber flesh

- Brown Turkey: purple skin and red flesh

- Adriatic: the variety most often used to make fig bars, which has a light green skin and pink- tan flesh.

Figs are lusciously sweet and feature a complex texture that combines the chewiness of their flesh, the smoothness of their skin, and the crunchiness of their seeds. In addition, since fresh figs are so delicate and perishable, some of their mystique comes from their relative rarity. Because of this, the majority of figs are dried, either by exposure to sunlight or through an artificial process, creating a sweet and nutritious dried fruit that can be enjoyed throughout the year. Figs, which are high in carbohydrates, vitamin K, and are a good source of minerals including calcium, magnesium, potassium, and manganese, when eaten fresh or dried. They are used in numerous desserts and baked goods, jams, and preserves, as well as in some savory and meat dishes.

\section{Review To Literature}

A detailed and exhaustive review of scientific literature highlights the following aspects of Fig as a research endeavor:

1. Fig is good source of carbohydrates and minerals like strontium, calcium, magnesium, phosphorus and iron. It has average protein and dietary fiber content with very low amount of fat.

2. Phytochemical studies on the leaves and fruits of the plant have shown that they are rich in phenolics, organic acids, and volatile compounds.

3. Volatile components of fig fruit showed the presence of vitamin $\mathrm{E}, \beta$-amyrin, stigmasterol, campesterol, oleic acid, isoamyl laurate and Y tocopherols majorly.

4. Some of the most interesting therapeutic effects of phytochemicals in fig include anticancer, hepatoprotective, hypoglycemic, hypolipidemic, and antimicrobial activities.

5. The barks, leaves, fruits are considered to be very effective in various treatments, such as diabetes, skin diseases, ulcers, dysentry, diarrohoea, stomachache, piles. Latex of the fig tree is widely used for warts, skin ulcers and sores, and taken as a purgative and vermifuge.

6. Phytochemicals in fig show significant immunostimulatory activities.

7. Alkaloids in fig are implicated in reducing inflammation by reducing leucocyte infiltration.

8. Alkaloids in fig exhibit prominent hepatoprotective activity in-vivo and are also implicated in reversal of rifampicin and carbon tetrachloride-induced liver damage.

9. Ficus tree latex shows promise as a potent antitumor agent.

10. Antioxidant capacity of fig correlates with the amount of flavonoids and phenols in the fruit.

11. The anti-pyretic effect of the ethanol extract of Ficus carica was comparable to that of Paracetamol, a standard anti-pyretic agent.

12. Fig contains a huge concentration of biocompatible antioxidant and antimicrobial with the least associated side effects.

13. Gallic acid, chlorogenic acid, (-)-epicatechin, syringic acid, rutin and psoralen are prominent flavonoids in fresh as well as dried figs.

14. Latex and leaf extracts of Fig have significant antimicrobial (antibacterial and antifungal) activity

A) PROXIMATE ANALYSIS:

\section{Materials And Methods}

This section of the research endeavor focused on identifying, characterizing and quantifying the various nutritional principles of Fig.

i) Samples utilized:

Locally procured fresh and dried figs purchased from Crawford market, Mumbai were used for analysis. Both the fresh and dried fruit samples were utilized separately for proximate analysis. 
ii) Processing of samples for Analysis:

The samples of fresh and dried figs were processed to yield an aqueous extract and an ash solution. The steps involved in the preparation of these solutions is detailed as follows:

Preparation of Ash solution: This involved the following distinct steps:

Drying of sample: A predetermined amount (usually in the range of 5-10g) of fresh fruit of fig and dried fig was weighed and placed in a clean, dry, empty petri plate. The plate was then placed in a hot air oven set at 100$110^{\circ} \mathrm{C}$ for around 45 minutes to an hour until the sample was dry. The plate was placed in a desiccator and its weight was recorded. The sample was dried subsequently at $90^{\circ} \mathrm{C}$ for 10 minutes intervals under the same conditions until the constant weight was obtained.

Incineration of sample: The entire contents of the petri plate were transferred into a clean, dry, pre-weighed empty silica crucible. The crucible was then placed in the incinerator to allow ashing of the sample. To facilitate evaporation of carbon from the sample, few drops of $0.1 \mathrm{~N} \mathrm{HNO}_{3}$ was added during incineration as an oxidizing agent. The sample was incinerated until a white ash residue was left behind. The crucible was then cooled in a desiccator.

Extraction of ash: The ash residue in the crucible was extracted by dissolving it in $1.0 \mathrm{ml}$ of $1: 1 \mathrm{HCl}$ and transferred into a $50 \mathrm{ml}$ of standard flask. Further, three washings of $0.5 \mathrm{ml}$ of $1: 1 \mathrm{HCl}$ each to completely extract all ash. The extracted ash in the $50 \mathrm{ml}$ ash solution was diluted with distilled water up to $50 \mathrm{ml}$ mark in the standard flask. This resultant ash solution was used for the analysis of minerals in the samples.

\section{Preparation of Aqueous extract:}

Around $1 \mathrm{~g}$ of the sample was taken in the mortar and pestle. Some amount of distilled water was added to the sample and it was macerated thoroughly. The aqueous phase was transferred into a $50 \mathrm{ml}$ of standard flask after filtration through a muslin cloth. Subsequent extracts were collected in the same manner and the extract was diluted to the $50 \mathrm{ml}$ mark with distilled water. This aqueous extract was used in the estimation of carbohydrates, reducing sugars, proteins, vitamin $\mathrm{C}$, and other nutrients in the sample.

\section{Proximate analysis:}

The following proximate principles were analyzed from the samples of Fresh and dried figs:

1. Estimation of Total carbohydrates by Anthrone method.

2. Estimation of Proteins by Folin Lowry method.

3. Estimation of Crude Fibre by Ashing method.

4. Determination of Moisture content.

5. Determination of Ash content.

6. Estimation of Calcium by EDTA method.

7. Estimation of Iron by Wong's method.

8. Estimation of Vitamin C by 2,4,6-Dichlorophenol indophenol blue method.

9. Estimation of reducing sugars by Benedict's method.

10. Estimation of sodium by flame photometry.

11. Estimation of potassium by flame photometry

12. Isolation of oils by solvent extraction.

In addition, the following characterization studies were carried out:

1. Thin Layer chromatography (TLC) of isolated oils:

- The lipid fraction obtained after solvent extraction was subjected to separation by Thin Layer chromatography (TLC).

- The stationary phase utilized was silica gel, the mobile phase was a mixture of petroleum ether and diethyl ether (1:1) and iodine vapors were used as the developing agent.

- The resolved components were characterized by calculating their respective $R_{f}$ values in the given chromatographic system.

2. Qualitative tests for sugars in aqueous extracts of fresh and dried figs:

- The aqueous extracts of both fresh and dried figs were subjected to qualitative tests for reducing sugars like Molisch test, Benedict's test, Fehling's test, Barfoed's test, Seliwanoff's test, Lead acetate test and Diphenylhydrazine (Osazone) test.

B) SENSORY EVALUATION:

Organoleptic analysis (or sensory evaluation) is a scientific discipline that applies the principles of experimental designs and statistical analysis to the use of human senses (sight, smell, taste, touch and hearing) for the purpose of evaluating consumer products. This is especially relevant as the human system's sensory output has 4 important characteristics: 
- $\quad$ Each sense is governed by specific biochemical activities and is capable of individual action.

- There is a synergistic effect of one or more senses in which case the biochemical effect is more sophisticated.

- The response to the stimulus by the sense is mediated through nervous transmission and is based on previous neural input i.e. memory.

- Sensory evaluation has many applications where the input governs both positive and negative responses.

Quality is the ultimate criteria for the desirability of any food product to the consumer. Sensory quality, as ascertained by the techniques of sensory evaluation, is a parameter of great importance to both the processor and the consumer. To the processor since it attracts consumers and the consumers since it satisfies the aesthetic and gustatory sense.

Sensory quality is a combination of different sensors of perception coming onto play in choosing and rating a food; which are as follows:

- Appearance- which can be judged by the eye; for example parameters like color, size, shape, uniformity and absence of defects are of first importance in food selection.

- Kinesthetics, the next important attribute concerns texture and consistency.

- Flavor, which embraces the sense of taste, smell and feelings. Odor assessment is done by sniffing food before putting it in the mouth. In - the- mouth assessment of flavor is done by putting food into the mouth and assessing the combinations of sensation.

- After taste measurements is done with sensations perceived after food is swallowed or rinsed in the mouth. The important considerations being that independent judgment in an atmosphere of relaxed concentration and free from any distraction should be possible.

Trained panel evaluations are used to detect and describe organoleptic characteristics of food products. Sensory evaluation is basically used for:

- Ingredients processing or packaging evaluation.

- Shelf life testing.

- Competitive comparisons.

- Research applications.

A quality test panelist must meet certain requirements before he participates in a sensory evaluation exercise:

1. No consumption of tobacco or food 2-3 hours before sensory evaluation is carried out.

2. Good health.

3. Absence of taste-blindness.

4. High degree of personal integrity.

5. Average sensitivity.

6. Intellectual curiosity and interest in sensory evaluation process.

\section{Assessment of organoleptic acceptability of Anjeer (Fig) halwa:}

For this study, a dessert using dried figs (Anjeer halwa) was developed as the product for evaluation. This dessert aimed to be low-calorie, highly nutritive preparation, which elevates the natural flavor and biochemical benefits of figs. In order to project the organoleptic appeal and acceptability of the nutritive fig product, sensory evaluation was carried out with a semi-trained panel. A panel comprising of $\mathbf{4 0}$ panelists (biostatistically significant number of panelists) were chosen for evaluation.

Panelists were to answer a detailed questionnaire based on both non-invasive and invasive parameters. Non-invasive parameters assessed the general awareness of the consumer w.r.t. the various nutritional qualities of fig, its incorporation into desserts and the acceptability of the idea of a dessert being made from figs. In the invasive section of the questionnaire, panelists graded the samples based on various sensory attributes. It also focused on the marketability of the product, its value for money, consumer preferences for product consumption and the overall acceptability of the Anjeer halwa. For this research, a comparative sensory evaluation between 2 samples was carried out; i.e. between Rawa (semolina) halva and Anjeer halva. Samples were presented in the following order to the panelists: 


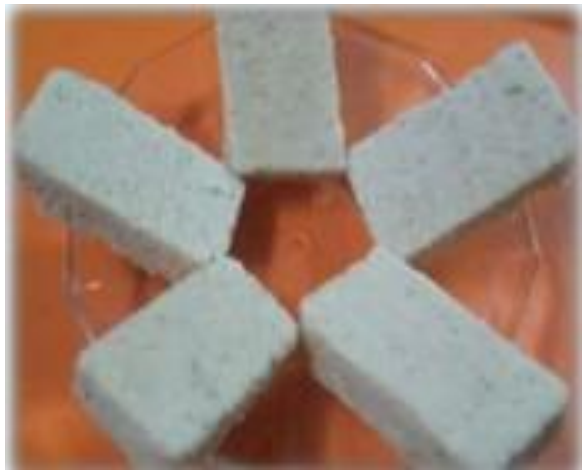

Sample A: Rawa halwa

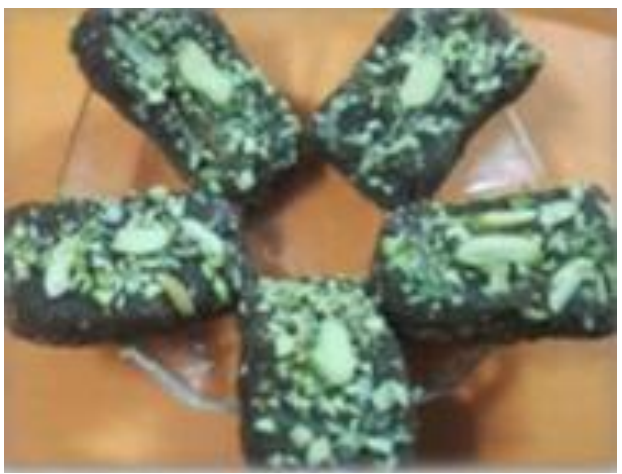

Sample B: Anjeer halwa

IV. Data Analysis: Non-Invasive

Panelist opinions on how often they consume figs:

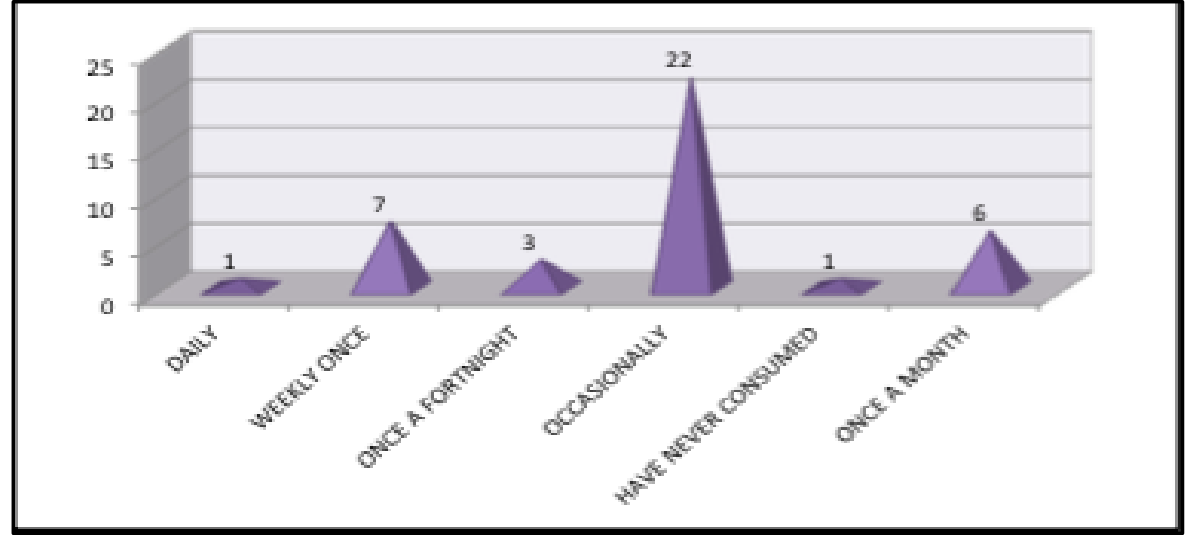

Panelists' awareness on the nutritional benefits of figs:

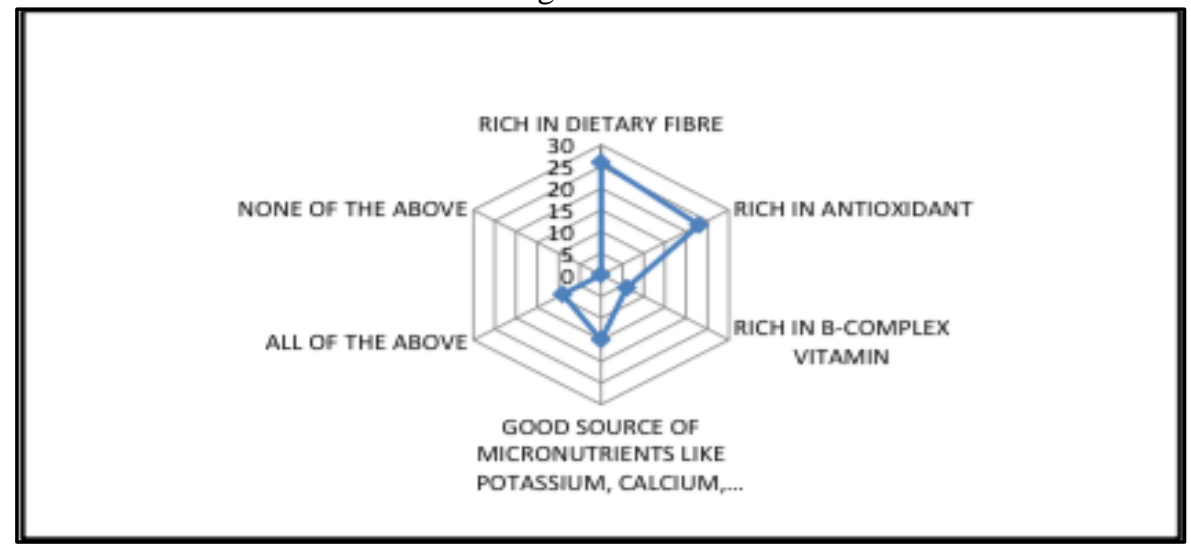

Panelist opinions on whether they prefer desserts prepared from figs:

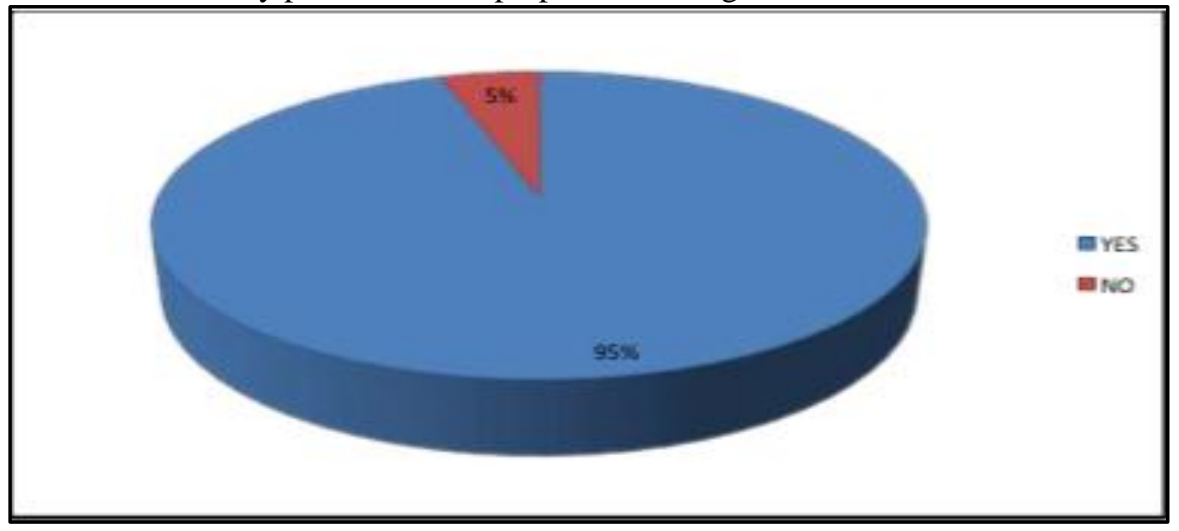


Panelist opinions on why people consume figs:

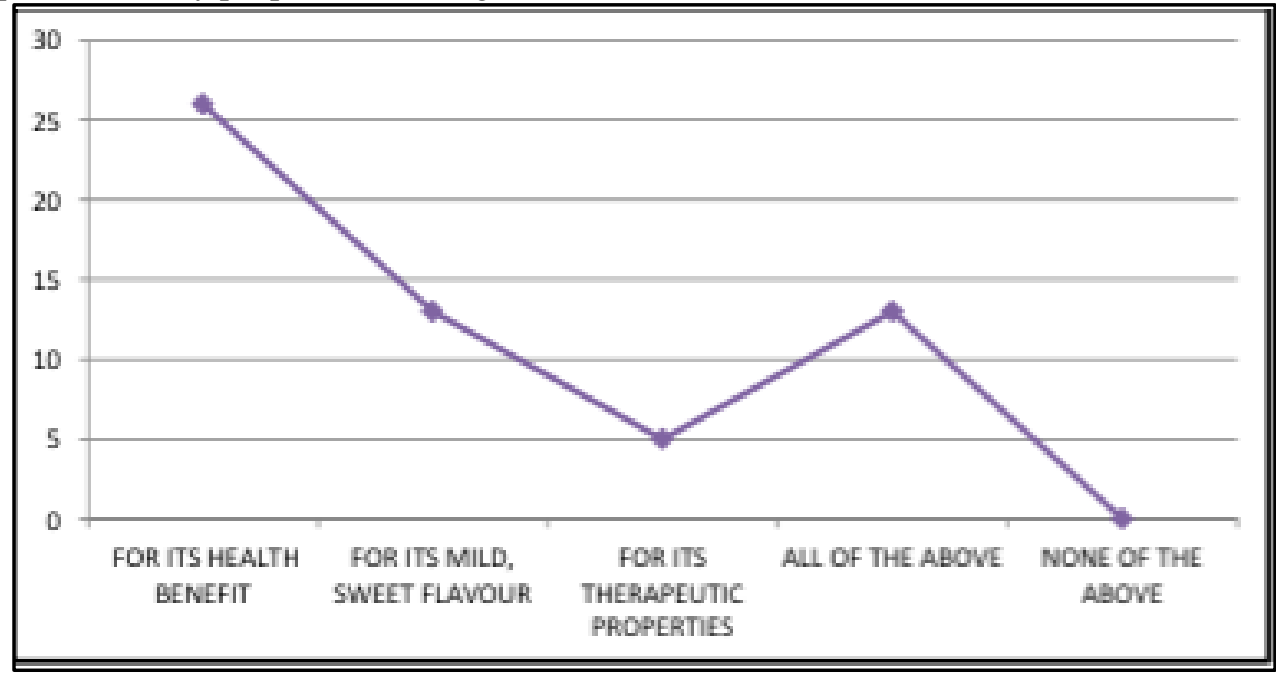

Panelist opinions on whether they would incorporate fig more frequently in their diet after knowing its various health benefits:

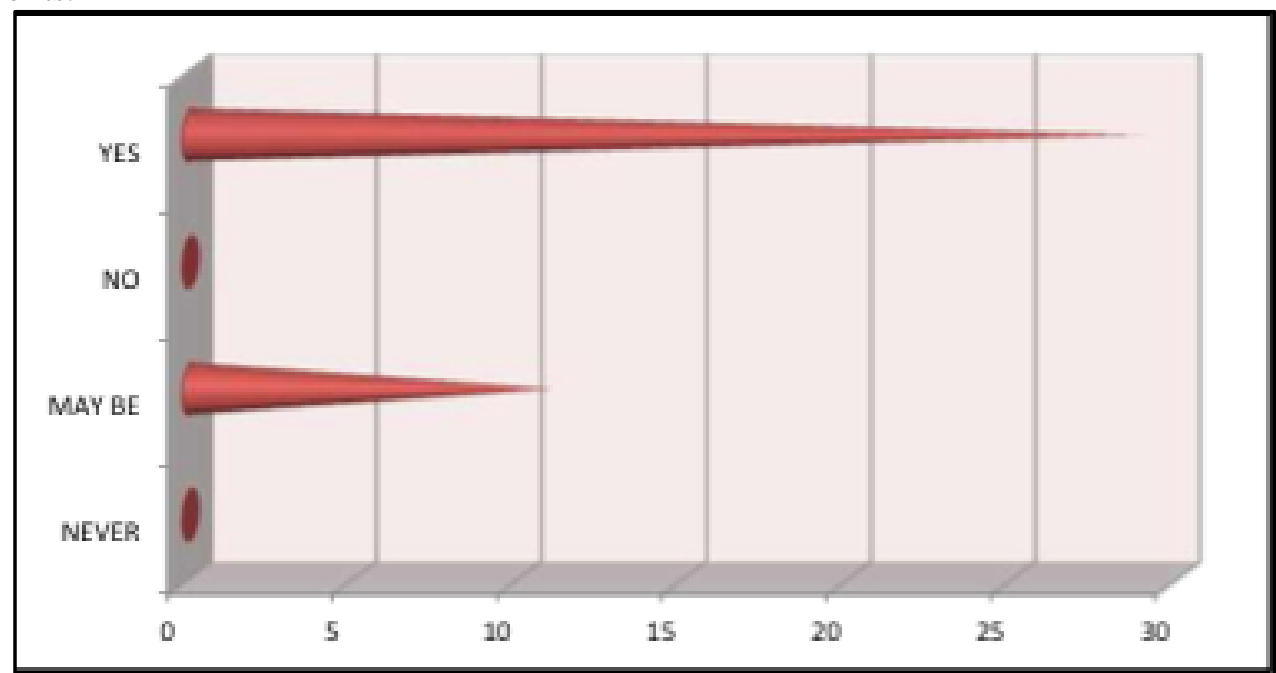

V. Data Analysis: Invasive

Panelist opinions on their overall preference between the two samples:

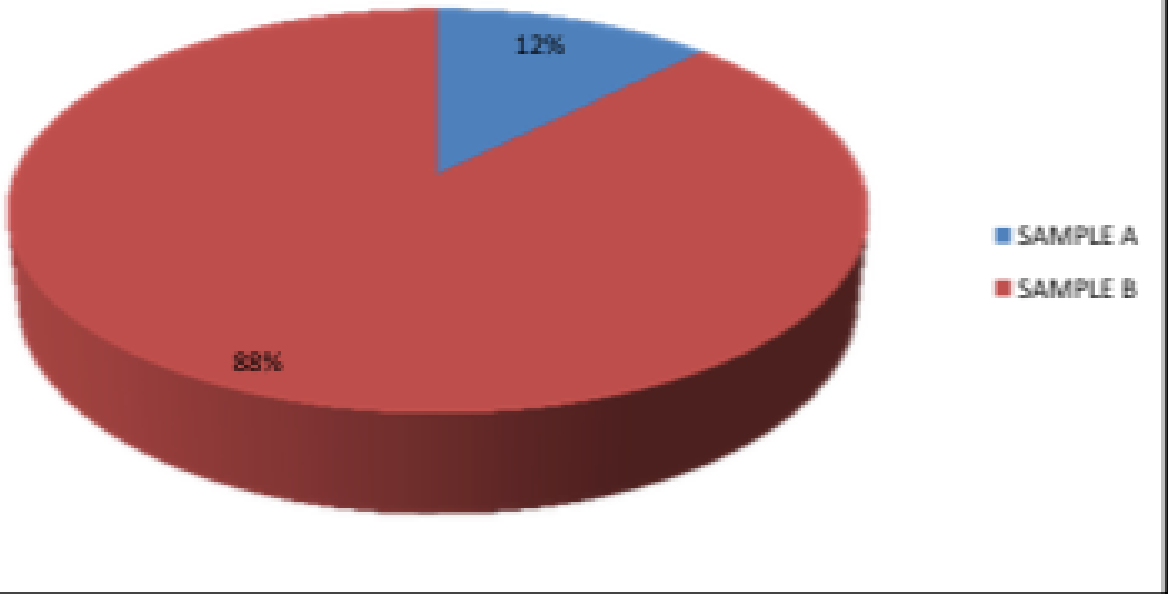


Panelist opinions on whether they would buy Anjeer halva if it were commercially available:

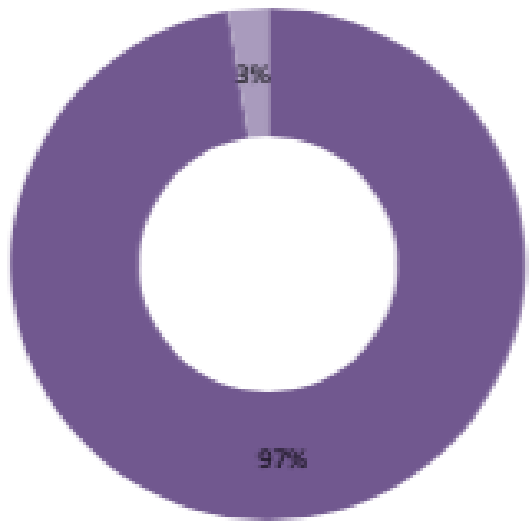

Panelist opinions in the pricing of Anjeer halva (Rs 75 for $100 \mathrm{~g}$ ):

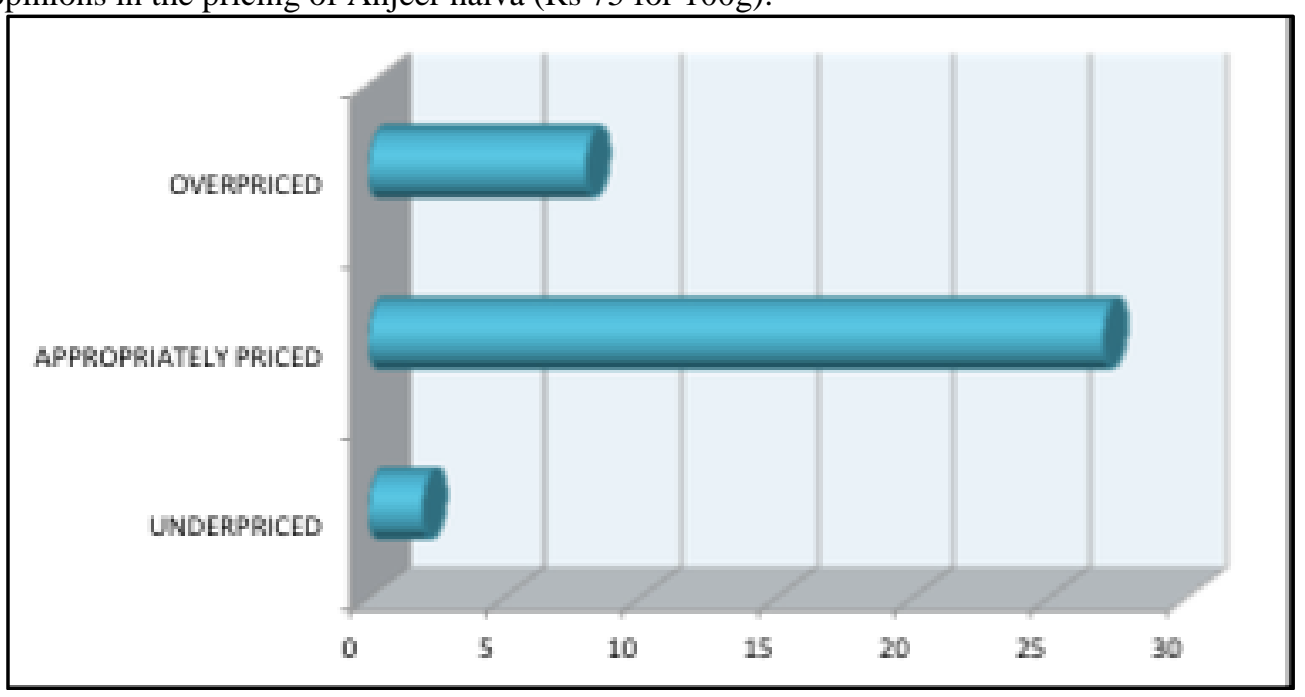

\section{Results}

A) PROXIMATE ANALYSIS:

\begin{tabular}{|l|c|c|}
\hline \multicolumn{1}{|c|}{ Nutrient } & $\begin{array}{c}\text { Amount in Fresh fig } \\
\text { (Per 100g) }\end{array}$ & $\begin{array}{c}\text { Amount in Dried fig } \\
\text { (Per 100g) }\end{array}$ \\
\hline Moisture & $79.94 \mathrm{~g}$ & $61.96 \mathrm{~g}$ \\
\hline Ash & $0.69 \mathrm{~g}$ & $0.89 \mathrm{~g}$ \\
\hline Carbohydrates & $20.0 \mathrm{~g}$ & $60.0 \mathrm{~g}$ \\
\hline Proteins & $1.02 \mathrm{~g}$ & $1.80 \mathrm{~g}$ \\
\hline Vitamin C & $1.86 \mathrm{mg}$ & $1.24 \mathrm{mg}$ \\
\hline Fiber & $2.10 \mathrm{~g}$ & $7.50 \mathrm{~g}$ \\
\hline Calcium & $104.2 \mathrm{mg}$ & $520 \mathrm{mg}$ \\
\hline Fat & $0.500 \mathrm{~g}$ & $0.959 \mathrm{~g}$ \\
\hline Nutrient & Amount in Fresh fig & Amount in Dried fig \\
& $($ Per $100 \mathrm{~g})$ & $10498.4 \mathrm{ppm}$ \\
\hline Sodium & $12995 \mathrm{ppm}$ & $53340 \mathrm{ppm}$ \\
\hline Potassium & $25336 \mathrm{ppm}$ & $41.33 \mathrm{~g}$ \\
\hline Reducing sugars & $14.76 \mathrm{~g}$ & $2.175 \mathrm{mg}$ \\
\hline Iron & $0.725 \mathrm{mg}$ & $61.6 \mathrm{mg}$ \\
\hline Phosphorus & $11.6 \mathrm{mg}$ & \\
\hline
\end{tabular}



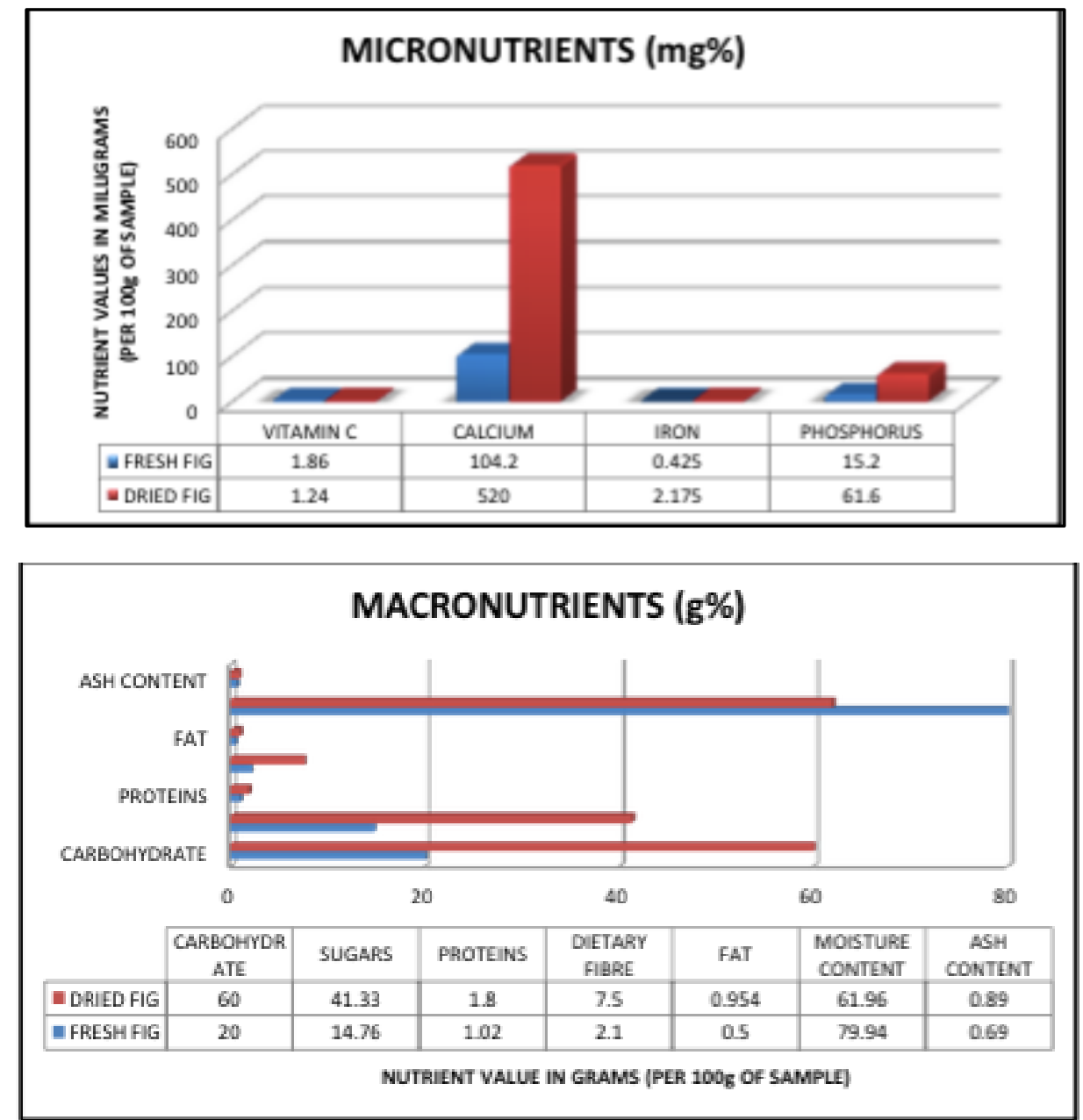

Macronutrients like carbohydrates, reducing sugars, proteins, and dietary fibre are more abundant in dried fig than fresh fig. Significant increase in values of these in dried fig is implicated due to the process of drying. This makes dried fig a more concentrated source of energy or a higher calorific value. However at the same time, moisture content is significantly reduced in dried fig. The ash content, a crude estimate of mineral content, increases on drying. Thus, dried fig exhibits a higher mineral content than fresh fig. As per the results obtained, it is evident that nutrients like calcium, phosphorus, iron, and potassium are abundant in dried fig as compared to fresh fig. The values of these nutrients increase on drying. However, during the process of drying, there is double the amount potassium in dried fig, in comparison with fresh fig. The low sodium to potassium ratio of fresh fig is significantly elevated in dried fig.

In the qualitative tests for reducing sugars, the extracts of raw and dried fig elucidated the presence of reducing monosaccharides, namely fructose or glucose. The osazone test further confirmed this fact as broomshaped osazones were obtained. However, the prominent sugar in both fresh and dried figs was confirmed as glucose because of the negative result of the Seliwanoff's test.

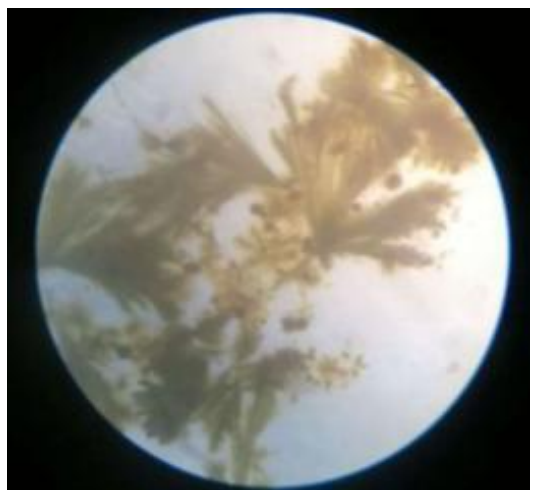

Glucosazones obtained in fresh and dried fig extracts 
The thin layer chromatography of the lipids isolated from fresh and dried figs yielded a resolution into two components each.

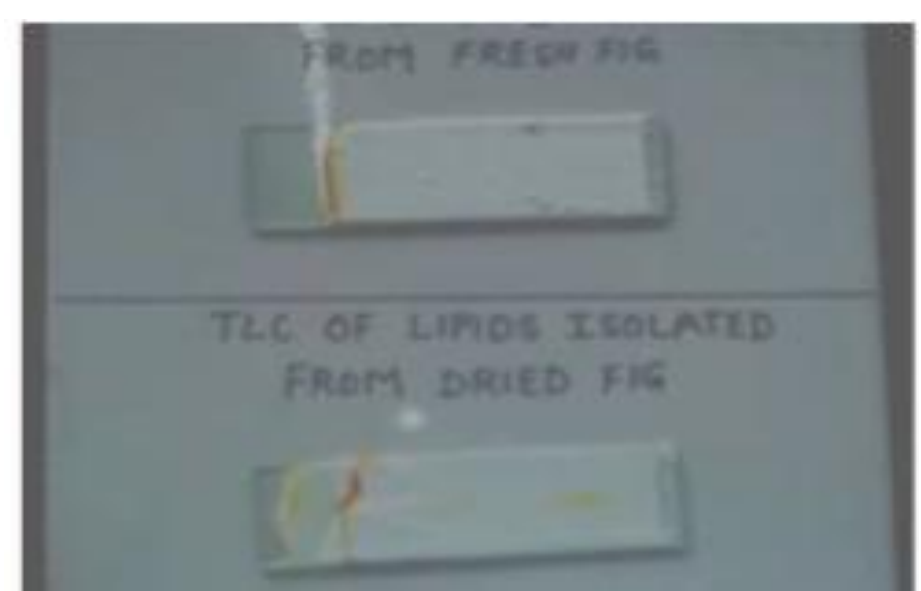

\section{TLC of lipids isolated from fresh fig and dried fig (Direction of run - right to left)}

The $\mathrm{R}_{\mathrm{f}}$ values of the lipid fractions obtained are detailed in the illustrations as follows:
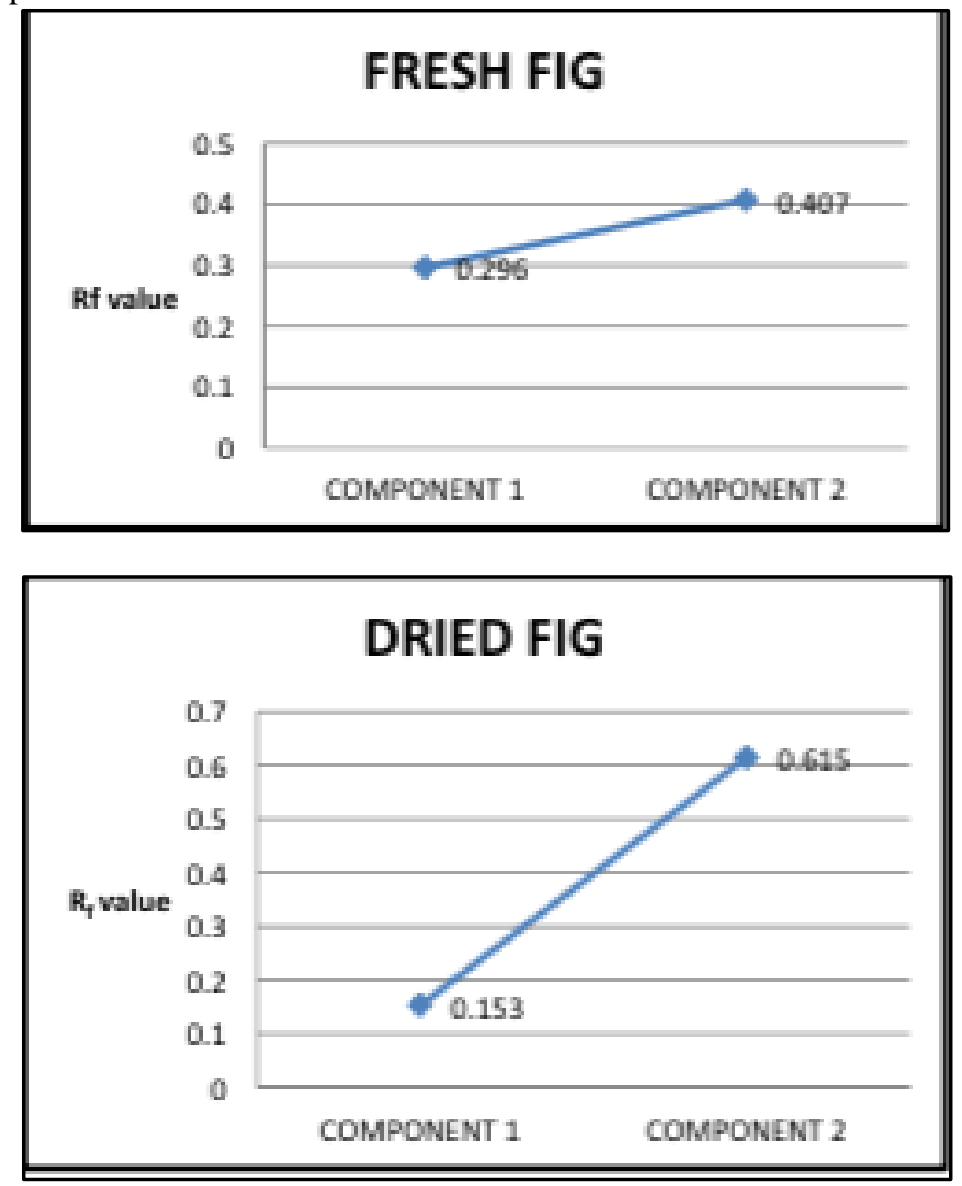

B) SENSORY EVALUATION:

1. $57 \%$ panelists consumed figs occasionally.

2. $63 \%$ panelists were aware that figs are a rich source of dietary fiber and antioxidants.

3. $95 \%$ panelists were aware that desserts are prepared from figs.

4. $63 \%$ panelists believed that people consume figs for their various health benefits.

5. $75 \%$ panelists mentioned that they would like to incorporate fig more frequently into their diets after knowing their various health benefits.

6. $97 \%$ panelists ascertained that they would buy anjeer halva if it were commercially marketed.

7. $68 \%$ panelists emphasized that the pricing of Fig halva is appropriate.

8. $88 \%$ panelists preferred Fig halva to rava halva. 


\section{Conclusion}

The proximate analysis shows that both raw and dried figs exhibit a balanced nutritional profile. The concentration of nutrients in dried figs makes them a rich source of energy with a high calorific value.

The trend of results of sensory evaluation confirms that there is minimum awareness about the health benefits of consumption of common fig. It is evident that consumption of common fig among a small proportion of people is basically because of their cultural food habits. The sensory evaluation procedure involving the semi-trained panelists exhibited high organoleptic acceptability for the product developed from common fig (dried form). Also, the product developed ascertained high VFM.

Fig is one of those few ingredients, which possesses the dual benefits of balanced nutrition and highly acceptable organoleptic profile. Thus it exhibits great potential to be marketed in the form of innovative products in the food industry. Lastly, the elucidated helath benefits of Figs pave way for discovering their untapped potential of marketing them as potential nutraceutical formulations to enhance human wellness.

\section{References}

[1]. Biochemical Methods-3rd Edition Sadashivam S, Manickam A. (New age international (P) Ltd. Publishers.(ISBN 81-224-0976-8)

[2]. Research Methodology Methods and Techniques-2nd Edition, -C.R. Kothari (New age international (P) Ltd. Publishers. ISBN 81224-1522-9).

[3]. Pearson's Composition and Analysis of Food by R.S.kirk, R. Sawyer and H.Egan.

[4]. Research Methodology Methods and Techniques-2nd Edition, -C.R.Kothari (New age international (P) Ltd. Publishers. ISBN 81224-1522-9).

[5]. Pearson's Composition and Analysis of Food by R.S.kirk,R. Sawyer and H.Egan.

[6]. Nutritive Value of India Foods- C. Gopalan, B V. Rama Sastri, S C. Balasubramaniam; National Institute of Nutrition, India Council of Medical Research, 1989. 